\title{
ПРЕДПРИНИМАТЕЛЬСКИЕ НАВЫКИ. КАК РАЗВИТИЕ ВНУТРЕННИХ, ГИБКИХ И ПРОФЕССИОНАЛЬНЫХ НАВЫКОВ ПОМОГАЕТ ФОРМИРОВАТЬ ПРЕДПРИНИМАТЕЛЬСКОЕ ПОВЕДЕНИЕ
}

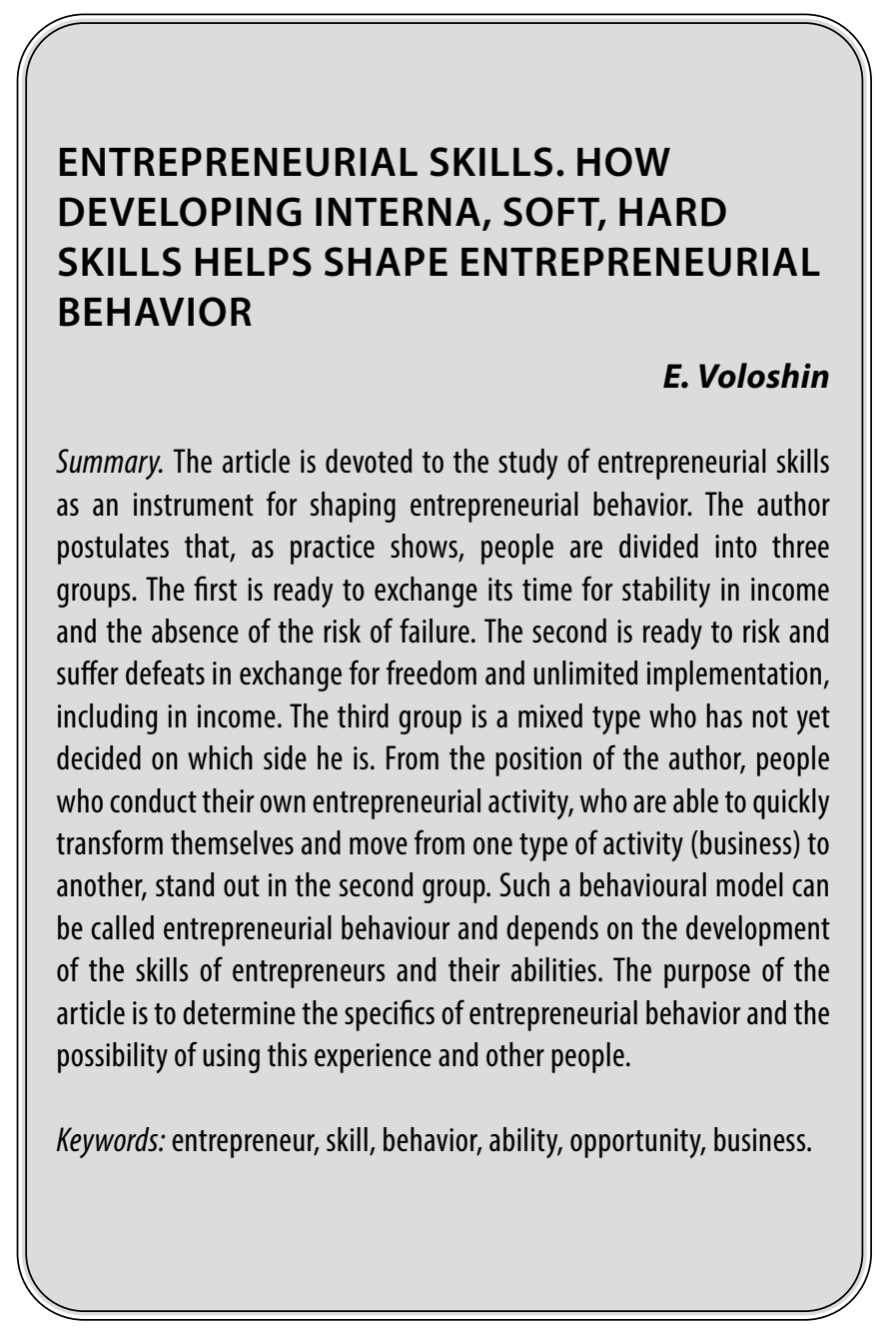

$\mathbf{M}$ ногие сотрудники корпораций мечтают о том, чтобы быть такими же свободными и финансово независимыми, как их некоторые друзья, занятые собственным бизнесом. При этом в большинстве случаев первые не могут это себе позволить, поскольку не способны переживать отдельные факторы влияние внешней среды (например, изменения условий на рынке из-за обстоятельств непреодолимой силы). Предпринимательство - образ жизни, который сопровождается множеством стрессовых ситуаций и в большинстве случаев требует принятия нестандартных решений. Предпринимателю нужно обладать такими чертами,

\author{
Волошин Евгений Викторович \\ К.ф.н., бизнес-коуч, лектор, Российский \\ университет дружбы народов; Дальневосточный \\ федеральный университет \\ ev@pivotpoint.team
}

Аннотация. Статья посвящена исследованию предпринимательских навыков как инструмента формирования предпринимательского поведения. Автор постулирует о том, что, как показывает практика, люди разделяются на три группы. Первая готова разменивать своё время на стабильность в доходе и отсутствие риска провала. Вторая готова рисковать и терпеть поражения в обмен на свободу и неограниченную реализацию, в том числе в доходе. Третья группа — смешанный тип, кто ещё не определился на какой он стороне. С позиции автора, во вторую группу выделяются люди, ведущие собственную предпринимательскую активность, способные быстро трансформировать себя и переходить от одного вида деятельности (бизнеса) к другому. Такая поведенческая модель может называться предпринимательским поведением и зависит от развитости навыков предпринимателей и их способностей. Цель статьи заключается в определении специфики предпринимательского поведения и возможности использования данного опыта и другими людьми.

Ключевые слова: предприниматель, навык, поведение, способность, в0зможность, бизнес.

как быстродействие, оперативность мышления, высокая стрессоустойчивость и, в большинстве сложных обстоятельств и при стратегическом планировании,пространственное видение отдельных событий. Исходя из этого, формируется модель поведения, которая помогает выстроить бизнес-процессы с использованием накопленного опыта предпринимателей. При этом, данная модель является многогранной и неповторимой, так как обладает наличием индивидуальных черт, которые не могут быть переняты в полном объеме. Однако, модель предпринимательского поведения, в определённой степени развития навыков, поможет 
Таблица 1. Пример задач и путей их достижения в модели предпринимательского поведения

\begin{tabular}{|l|l|}
\hline Задачи & Методы достижения \\
\hline $\begin{array}{l}\text { Смена работы на существенно более любимую } \\
\text { и высокооплачиваемую }\end{array}$ & $\begin{array}{l}\text { Действовать на опережение и не ждать «лучших» рыночных условий } \\
\text { Выстраивание собственного развития и профессионального роста, }\end{array}$ \\
\hline Развитие новых направлений в бизнесе & $\begin{array}{l}\text { Запуск новых продуктов и услуг, освоение новых сегментов, } \\
\text { масштабирование }\end{array}$ \\
\hline
\end{tabular}

Источник: составлено автором.

Таблица 2. Пример базовых навыков для построения эффективного бизнеса и корпоративной карьеры

\begin{tabular}{|c|c|}
\hline Навык & Описание \\
\hline ВИДЕНИЕ И ЦЕЛИ & $\begin{array}{l}\text { Видение - умение проецировать идеальный результат в будущем, определяет направление } \\
\text { движения компании; данный навык крайне необходим для стратегического планирования. } \\
\text { Инструмент - Стратегическая сессия. } \\
\text { Цели - умение «оцифровывать» метрики краткосрочного идеального результата, а также } \\
\text { декомпозировать большую долгосрочную цель на достижимые этапы. } \\
\text { Инструмент - S.M.A.R.T. }\end{array}$ \\
\hline ЛИДЕРСТВО И КОММУНИКАЦИЯ & $\begin{array}{l}\text { Лидерство - умение повести за собой людей, создать в группе между людьми связи, } \\
\text { способствующие решению задач; умение объединить людей для достижения целей. } \\
\text { Инструмент - публичные выступления. } \\
\text { Коммуникация - умение выстраивать взаимодействие с/между людьми. } \\
\text { Инструмент - сеть деловых контактов. }\end{array}$ \\
\hline ОБРАТНАЯ СВЯЗЬ И РАЗВИТИЕ & $\begin{array}{l}\text { Обратная связь - умение получать информацию об опыте контрагента. } \\
\text { Инструмент - Customer Development (исследование покупателя). } \\
\text { Развитие - умение организовывать поступательное движение - переходить от одного } \\
\text { состояния (процесса) к другому. } \\
\text { Инструмент - HADI-циклы. }\end{array}$ \\
\hline МОТИВАЦИЯ & $\begin{array}{l}\text { Мотивация - умение стимулировать самого себя и других к конкретным действиям } \\
\text { на достижение целей (личных и организации) через переход на уровень ценностей. } \\
\text { Инструмент - целеполагание. }\end{array}$ \\
\hline КОНКРЕТНЫЕ ШАГИ & $\begin{array}{l}\text { Конкретные шаги - умение применять структурный подход к переводу людей, команд } \\
\text { или организаций из текущего состояния в желаемое будущее через спланированные } \\
\text { и согласованные действия. } \\
\text { Инструмент - управление изменениями. }\end{array}$ \\
\hline РОЛИ И ОТВЕТСТВЕННОСТЬ & $\begin{array}{l}\text { Роли - умение распределять обязанности и наделять полномочиями для достижения } \\
\text { стратегических целей организации. } \\
\text { Инструмент - управление проектом/командой. } \\
\text { Ответственность - умение наделять правом и обязанностью отвечать за свои действия } \\
\text { и взятые на себя обязательства, согласно договорённостям. } \\
\text { Инструмент - делегирование. }\end{array}$ \\
\hline ЯСНЫЕ ЗАДАЧИ & $\begin{array}{l}\text { Ясные задачи - умение чётко формулировать требования, предъявляемые к решению } \\
\text { проблемы или достижению поставленных целей, основанные на измеримых метриках. } \\
\text { Инструмент — OKR, KPI, S.M.A.R.T. }\end{array}$ \\
\hline
\end{tabular}

Источник: составлено автором

в построении карьеры специалистам, не видящим себя в предпринимательстве.

В целом предпринимательское поведение является довольно сложным процессом, который формируется на протяжении длительного опыта деятельности предпринимателя. Одной из основных особенностей предпринимательского поведения является его адаптируемость и возможность быстрого перехода в новые виды деятельности. Особенно это проявилось в период пандемии, когда многим пришлось трансформировать, закрыть или перейти в другой. Приведём примеры.

Так, например, предприниматель из Тольятти вложил более миллиона рублей в перенастройку цеха по производству арахисовой пасты на выпуск антисептиков. Такая трансформация бизнеса позволила переориентироваться на новые требования экономики 


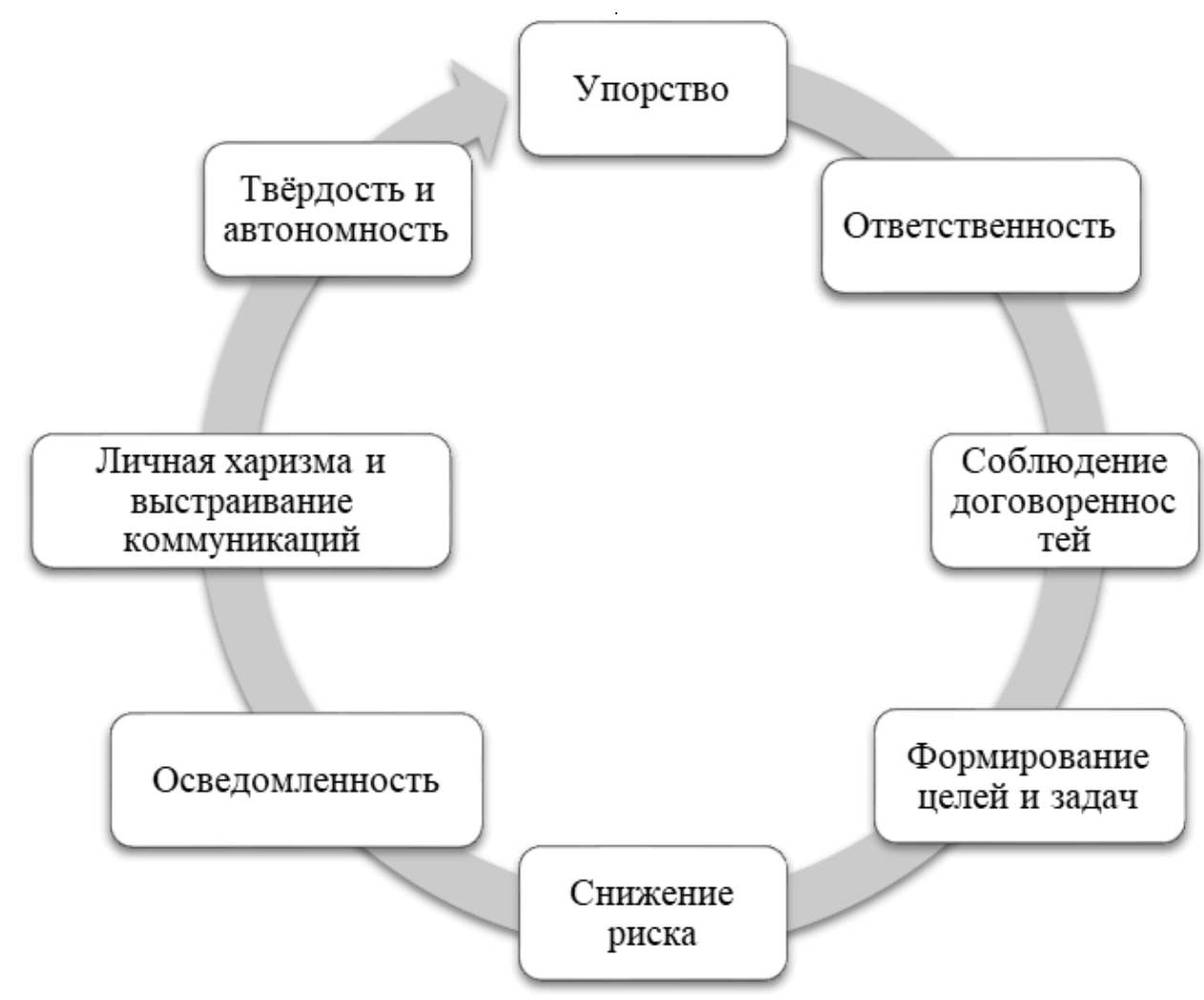

Рис. 1. Навыки, которые помогают формировать предпринимательское поведение Источник: составлено автором

предпринимателю за несколько месяцев и получать стабильную прибыль [1].

Другой предпринимательский союз из Курска, основным видом деятельности которого был пошив сценических костюмов, смог быстро переключиться на пошив медицинских масок [2].

Производители наполнителя для животных, потеряв ряд крупных заказчиков в результате закрытия многих зоомагазинов, также в 2020 году оказалась на грани банкротства. В результате предприниматель переориентировался напрямую на потребителя. Создал сайт, провёл промоакции, заключил договор с курьерской службой и стал доставлять наполнитель до двери. Как итог - продажи выросли в два раза [5].

Однако были и предприниматели, которые полностью свернули свой бизнес, встали на учет в Центры занятости или устроились на работу в качестве наемных сотрудников. То есть данный пример показывает, что в предпринимательстве также выживает сильнейший, обладающий всеми навыками «предпринимательское поведения», представляющего некую модель [3]. Данная модель строится на постановке ряда задач, которые систематизированы в таблице 1.
Кроме перечисленного предприниматель должен обладать упорством, умением находить возможности для решения проблем, выстраивать стратегию собственного роста, быть коммуникабельным и ответственным.

Переходя к исследованию навыков, которые помогают формировать предпринимательское поведение, стоит подчеркнуть, что наиболее частой проблемой и причиной неудач выступает снятие или перекладывание с себя ответственности за выполненные действия. Как пример, предприниматель разрабатывал логотипы и рекламу. Когда заказчик предъявил ему претензию и попросил переделать все в короткие сроки - предприниматель просто ушел с рынка, удалил свой аккаунт и перешел работать в другую сферу. Таких примеров огромное множество и свойственны они практически каждой отрасли. Люди бросают всё при первых сложностях и уходят из бизнеса, снимая с себя ответственность за результат. Это позволяет сделать вывод о том, что наиболее значимым навыком, определяющим формат предпринимательского поведения, является упорство [4]. Необходимо фокусировать себя, быть настойчивым, чтобы решить проблему и обойти препятствие. К тому же важно брать ответственность за достижение целей и выполнение задач. В целом, обобщающая и да- 
леко не полная систематизация навыков, которые помогают формировать предпринимательское поведение, приведена на рисунке 1.

Важно понимать, что индивидуальная поведенческая модель предпринимателя формируется годами и ее трансформация может привести к новым результатам. Сильные стороны вытянут остальное. Также необходимо еще раз отметить, что далеко не каждый сможет применить на себе эту модель предпринимательского поведения. И для этого есть следующие причины:

1. Далеко не всем такое поведение свойственно. Предпринимательское поведение носит рисковый характер и не каждый сможет легко переносить потери, как финансового, так и личностного характера.

2. Многие люди «рисуют» перед собой набор установок, которые не могут нарушить в силу тех или иных причин. Это сложности в общении с известными людьми, что часто имеет место в бизнесе, принятие аксиом управления своими финансами, повышенная осторожность в общении даже с друзьями.

3. Наличие страха и тревоги мешает принимать решения, что является «проблемой» и не позволяют сформировать предпринимательскую модель поведения.

Данный список может быть продолжен, однако любая из перечисленных черт не носит исключительный характер - людям свойственно «находить» проблемы, мешающие им выстраивать собственный бизнес. Тем не менее изучение предпринимательского поведения может устранить ряд подобных ограничений и помочь перестроиться любому человеку. Самым важным здесь является наличие желания и осознание той степени ответственности, которая закладывается в ведение бизнеса, вне зависимости от масштаба и уровня задач.

Таким образом, внутренние предпринимательские навыки имеются у большинства выбравших для себя путь предпринимательства и свойственны, в целом, каждому человеку. Однако их развитие позволяет формировать предпринимательское поведение, свойственное участникам бизнеса работающим на себя. Здесь также стоит отметить, что именно предпринимательские навыки являются залогом успеха развития бизнеса и позволяют выстоять в сложных рыночных условиях, а также быстро адаптироваться к нестабильности, неопределённости и меняющейся внешней среде. В таблице 2 мы рассмотрим основные навыки и инструменты как для построения собственного бизнеса, так и эффективной карьеры в корпорациях.

Мы приходим к выводу, что общей модели предпринимательского поведения не существует - она формируется в каждом случае индивидуально и выстраивается под процессы, происходящие в среде самого предпринимателя. Тем не менее для того, чтобы не бояться делать ошибки и не избегать негативных моментов в работе, целесообразно изучать опыт других предпринимателей - возможно, что их ключевые навыки, сформировавшие их уникальную модель предпринимательского поведения, дадут другим последователям базис для создания собственной модели успешного ведения бизнеса и построения эффективной карьеры.

\section{ЛИТЕРАТУРА}

1. Вирус перемен: как малый бизнес России поменялся в пандемию и выиграл. — 27.06.2020// PИА Новости. — ULR: https://ria.ru/20200627/1573549285. html (дата обращения: 17.06.2021)

2. Камнева К. Крупный бизнес переоборудовал производства под выпуск антисептиков. - 10.04.2020 // Российская газета. — ULR: https:// rg.ru/2020/04/10/krupnyj-biznes-pereoborudoval-proizvodstva-pod-vypusk-antiseptikov.html (дата обращения: 17.06.2021)

3. Предпринимательское Поведение, способы его формирования и целенаправленного развития. - 30.03.2020 // Портал VC.RU.— ULR: https:// vc.ru/u/10763-alexandr-bakeev/116164-predprinimatelskoe-povedenie-sposoby-ego-formirovaniya-i-celenapravlennogo-razvitiya (дата обращения: 17.06.2021)

4. Проблемы в бизнесе в период пандемии: выгоднее продать его или стать банкротом? — 20.07.2020 // ГAPAHT. — ULR: https://www.garant.ru/ia/ opinion/author/postanyuk/1401376/ (дата обращения: 17.06.2021)

5. Ушли в минус: сколько российский бизнес потерял в кризис // Портал «Сбербанк Бизнес».— ULR: https://www.sberbank.ru/ru/s_m_business/pro_ business/poteri-rossijskogo-biznesa-ot-koronavirusa/ (дата обращения: 17.06.2021) 